\title{
Normal Solid Gastric Emptying Values Measured by Scintigraphy Using Asian-style Meal: A Multicenter Study in Healthy Volunteers
}

\author{
Pataramon Vasavid, ${ }^{1}$ Tawatchai Chaiwatanarat, ${ }^{1}$ Pawana Pusuwan, ${ }^{2}$ Chanika Sritara, ${ }^{3}$ Krisana Roysri, ${ }^{4}$ Sirianong \\ Namwongprom ${ }^{5}$ Pichit Kuanrakcharoen, ${ }^{6}$ Teerapon Premprabha, ${ }^{7}$ Kitti Chunlertrith, ${ }^{8}$ Satawat Thongsawat, ${ }^{9}$ \\ Siam Sirinthornpunya, ${ }^{10}$ Bancha Ovartlarnporn, ${ }^{11}$ Udom Kachintorn, ${ }^{12}$ Somchai Leelakusolvong, ${ }^{12}$ Chomsri Kositchaiwat, $^{13}$ \\ Suriya Chakkaphak ${ }^{13}$ and Sutep Gonlachanvit ${ }^{14 *}$

\begin{abstract}
${ }^{1}$ Department of Radiology, Faculty of Medicine, Chulalongkorn University, Bangkok, Thailand; ${ }^{2}$ Department of Radiology, Faculty of Medicine, Siriraj Hospital, Mahidol University, Bangkok, Thailand; ${ }^{3}$ Department of Radiology, Faculty of Medicine Ramathibodi Hospital, Mahidol University, Bangkok, Thailand; ' Department of Radiology, Faculty of Medicine, Khon Kaen University, Khon Kaen, Thailand; '5epartment of Radiology, Faculty of Medicine, Chiang Mai University, Chiangmai, Thailand; ' Department of Radiology, Rajavithi Hospital, Bangkok, Thailand; 'Department of Radiology, Faculty of Medicine, Prince of Songkla University, Songkhla, Thailand; ${ }^{8}$ Department of Medicine, Faculty of Medicine, Khon Kaen University, Khon Kaen, Thailand; ' Department of Internal Medicine, Faculty of Medicine, Chiang Mai University, Chiangmai, Thailand; ${ }^{10}$ Department of Medicine, Rajavithi Hospital, Bangkok, Thailand; ${ }^{11}$ Department of Medicine, Faculty of Medicine, Prince of Songkla University, Songkhla, Thailand; ${ }^{12}$ Department of Medicine, Faculty of Medicine, Siriraj Hospital, Mahidol University, Bangkok, Thailand; ${ }^{13}$ Department of Medicine, Faculty of Medicine Ramathibodi Hospital, Mahidol University, Bangkok, Thailand; and ${ }^{14}$ GI Motility Research Unit, Division of Gastroenterology, Department of Medicine Faculty of Medicine, Chulalongkorn University, Bangkok, Thailand
\end{abstract}

\section{Background/Aims}

To report gastric emptying scintigraphy, normal values should be established for a specific protocol. The aim of this study was to provide normal gastric emptying values and determine factors affecting gastric emptying using Asian rice-based meal in healthy volunteers.

Received: November 7, 2013 Revised: May 1, 2014 Accepted: May 29, 2014

(c) This is an Open Access article distributed under the terms of the Creative Commons Attribution Non-Commercial License (http://creativecommons org/licenses/by-nc/3.0) which permits unrestricted non-commercial use, distribution, and reproduction in any medium, provided the original work is properly cited.

*Correspondence: Sutep Gonlachanvit, MD

Division of Gastroenterology, Department of Medicine, Faculty of Medicine, Chulalongkorn University, 1873 King Chulalongkorn Memorial Hospital, Rama 4 Road, Patumwan, Bangkok 10330, Thailand

Tel: +66-2-256-4265, Fax: +66-2-252-3540, E-mail: gsutep@hotmail.com

Financial support: This work was supported by the Thai Neurogastroenterology and Motility Society and a grant from The Gastroenterological Association of Thailand.

Conflicts of interest: None.

Author contributions: All authors designed the research study; Pataramon Vasavid, Tawatchai Chaiwatanarat, Pawana Pusuwan, Chanika Sritara, Krisana Roysri, Sirianong Namwongprom, Pichit Kuanrakcharoen and Teerapon Premprabha performed the research study; Pataramon Vasavid analyzed the data and wrote the paper; Tawatchai Chaiwatanarat, Pawana Pusuwan, Chanika Sritara, Krisana Roysri, Sirianong Namwongprom, Pichit Kuanrakcharoen, Teerapon Premprabha, Kitti Chunlertrith, Satawat Thongsawat, Siam Sirinthornpunya, Bancha Ovartlarnporn, Udom Kachintorn, Somchai Leelakusolvong, Chomsri Kositchaiwat, Suriya Chakkaphak and Sutep Gonlachanvit edited the paper.

ORCID: Pataramon Vasavid, http://orcid.org/0000-0002-0067-8319; Tawatchai Chaiwatanarat, http://orcid.org/0000-0002-0562-1223; Pawana Pusuwan, http://orcid.org/0000-0002-1518-3837; Chanika Sritara, http://orcid.org/0000-0001-7607-1786; Krisana Roysri, http://orcid.org/0000-0002-0745-1088; Teerapon Premprabha, http://orcid.org/0000-0003-3630-1203; Kitti Chunlertrith, http://orcid.org/0000-0003-1833-6744; Satawat Thongsawat, http://orcid.org/0000-0003-3302-3930; Bancha Ovartlarnporn, http://orcid.org/0000-0001-9464-885X; Udom Kachintorn, http://orcid.org/0000-0001-7776-5157; Somchai Leelakusolvong, http://orcid.org/0000-0001-7104-2759; Chomsri Kositchaiwat, http://orcid.org/0000-0002-8253-8132; Suriya Chakkaphak, http://orcid.org/0000-0001-7314-1523; Sutep Gonlachanvit, http://orcid.org/0000-0002-8279-8778. 


\section{Methods}

One hundred and ninety-two healthy volunteers were included at 7 tertiary care centers across Thailand. Gastric emptying scintigraphy was acquired in 45 degree left anterior oblique view immediately after ingestion of a $267 \mathrm{kcal}$ steamed-rice with technetium-99m labeled-microwaved egg meal with $100 \mathrm{~mL}$ water for up to 4 hours.

\section{Results}

One hundred and eighty-nine volunteers (99 females, age $43 \pm 14$ years) completed the study. The medians (5-95th percentiles) of lag time, gastric emptying half time (GE $\left.T_{1 / 2}\right)$ and percent gastric retentions at 2 and 4 hours for all volunteers were 18.6 (0.5-39.1) minutes, 68.7 (45.1-107.8) minutes, $16.3 \%(2.7-49.8 \%)$ and $1.1 \%(0.2-8.8 \%)$, respectively. Female volunteers had significantly slower gastric emptying compared to male (GE T1/2, 74 [48-115] minutes vs. 63 (41-96) minutes; $P<0.05$ ). Female volunteers who were in luteal phase of menstrual cycle had significantly slower gastric emptying compared to those in follicular phase or menopausal status (GE T1/2, 85 [66-102] mintes vs. 69 [50-120] minutes or 72 [47-109] minutes, $P<0.05$ ). All of smoking volunteers were male. Smoker male volunteers had significantly faster gastric emptying compared to non-smoker males (GE T/12, 56 [44-80] minutes vs. 67 [44-100] minutes, $P<0.05$ ). Age, body mass index and alcohol consumption habits did not affect gastric emptying values.

\section{Conclusions}

A steamed-rice with microwaved egg meal was well tolerated by healthy volunteers. Gender, menstrual status and smoking status were found to affect solid gastric emptying.

\section{(J Neurogastroenterol Motil 2014;20:371-378)}

\section{Key Words}

Gastric emptying; Healthy volunteers; Oryza sativa (Rice); Radionuclide imaging; Smoking

\section{Introduction}

Gastric emptying scintigraphy has been considered as gold standard in gastric emptying measurement due to its physiologic, quantitative and non-invasive nature. ${ }^{1}$ However, gastric emptying values are dependent on various factors such as meal composition and consistency, ${ }^{2}$ body position, ${ }^{3}$ smoking, ${ }^{4}$ gender, ${ }^{5}$ phase of menstrual cycle ${ }^{6}$ and time of day the study is performed. ${ }^{7}$ Therefore, study protocol standardization and established normal values for such protocol are needed for accurate interpretation of the test. ${ }^{8}$

The normal solid gastric emptying values have been established from multi-institutional studies in the United States, Canada and Europe, using Western-style meal consisting of a scrambled egg substitute, 2 slices of bread, strawberry jam and water.' However, most of Thai and Asian people are not familiar with that Western-style meal. The normal solid gastric emptying values using Asian-style meal with large sample size has not been reported, although there were some small studies using rice-based meal $^{10}$ or some studies in Asia using Western-style meal. ${ }^{11,12}$

The aims of this study were to standardize solid gastric emptying protocol in 7 nuclear medicine centers in Thailand and establish normal solid gastric emptying value using Asian-style meal.

\section{Materials and Methods}

\section{Subjects}

One hundred and ninety-two healthy volunteers were invited to participate with the studies at 7 tertiary care centers across Thailand (1 in the Southern, 1 in the Northern, 1 in the North-Eastern and 4 in Bangkok) using quota sampling into male and female subgroups with age $\geq 18$ and $<30, \geq 30$ and $<40, \geq 40$ and $<50, \geq 50$ and $<60$ and $\geq 60$.

The volunteers with any disturbed gastrointestinal symptom, history of gastroenteritis within the last 3 months, previous intra-abdominal surgery except for appendectomy or tubal ligation, an underlying medical illness, current medication except contraceptive pill, sexually active women who used unreliable contraceptive method(s) or lactation women were not allowed to participate in this study.

Some demographic data, smoking status and alcohol consumption status of all volunteers were recorded. Those who have never smoked, had been smoking (at least 1 cigarette/day for $>1$ year) but quitted 1 year or more before the study and still smoke (at least 1 cigarette/day for $>1$ year) were classified as non-smoker, ex-smoker and smoker, respectively. Smoker volunteers were 
advised to stop smoking at least 24 hours before the study. Those who have never consumed alcohol beverage (never or rarely consumed alcohol), had been consuming (occasionally or regularly consumed alcohol) but quitted 1 year or more before the study, and still consume (occasionally or regularly consumed alcohol) were classified as non-drinker, ex-drinker and drinker, respectively.

For female volunteers, last menstrual cycle and menstrual interval as well as regularity and contraceptive method was interviewed for evaluation of phase of menstrual cycle and possible pregnancy. Female volunteers who were in the last 14 days of the menstrual cycle were decided to be in luteal phase. Those who were in the days before the last 14 days of the menstrual cycle were decided to be in follicular phase. Those with menstrual irregularity or exact menstrual history cannot be taken were excluded from analysis regarding phase of menstrual cycle.

All subjects provided written informed consent before entering the study. The study was approved by ethics committees of every institution participating in this study.

\section{Meal}

The testing meal consisted of $100 \mathrm{~g}$ steamed rice, a microwaved labeled egg and $100 \mathrm{~mL}$ water. The microwaved labeled egg was prepared from 65-70 g whole egg that was mixed with 5 $\mathrm{mL}$ vegetable oil, $10 \mathrm{~mL}$ water and $37 \mathrm{MBq}{ }^{99 \mathrm{~m}} \mathrm{Tc}$ phytate or sulfur colloid. The total calorie of the meal was $267 \mathrm{kcal}(57 \%$ carbohydrate, $23 \%$ fat and $19 \%$ protein). The sauce which had soy sauce and salt as the main ingredients was provided to volunteers to improve the meal taste.

\section{Scintigraphic Technique}

After at least 6 hours fasting, volunteers were instructed to ingest the test meal within 10 minutes. 1 minute/frame scintigraphic images were acquired into a $128 \times 128$ matrix using single head of gamma camera equipped with general purpose collimator in the upright position and 45 degree left anterior oblique view at $0-30$ minutes, $0.5,1,1.5,2,3$ and 4 hours after the meal ingestion. As some patients have to be in standing position to have the gastric region in the gamma camera field, those who could not stand for 30 minutes during 0-30 minute dynamic acquisition for accurate evaluation of lag time, serial static images were acquired at $0,5,10,15,20,25$ and 30 minutes instead.

\section{Gastric Emptying Analysis}

After motion correction, the gastric regions of interest were drawn. The data were corrected for time decay. Fractional gastric retentions were then fitted by modified power exponential func$\operatorname{tion}^{13}$ as $y(t)=1-\left(1-e^{-k t}\right)^{\beta}$ where $y(t)$ was fractional gastric retention at time $\mathrm{t}, \mathrm{t}$ was time (minute), $\mathrm{k}$ was gastric emptying rate (minute $^{-1}$ ) and $\beta$ was extrapolated $y$-intercept from the terminal portion of the curve. If the goodness of fit $\left(\mathrm{r}^{2}\right)$ between the fractional meal retention data and modified power exponential model was less than 0.9 , only percents gastric retention at $0.5,1,1.5,2,3$ and 4 hours were calculated. If the $r^{2}$ was equal to or more than
A

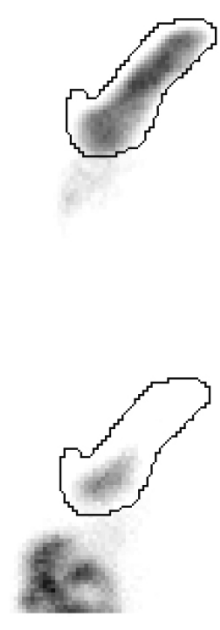




B

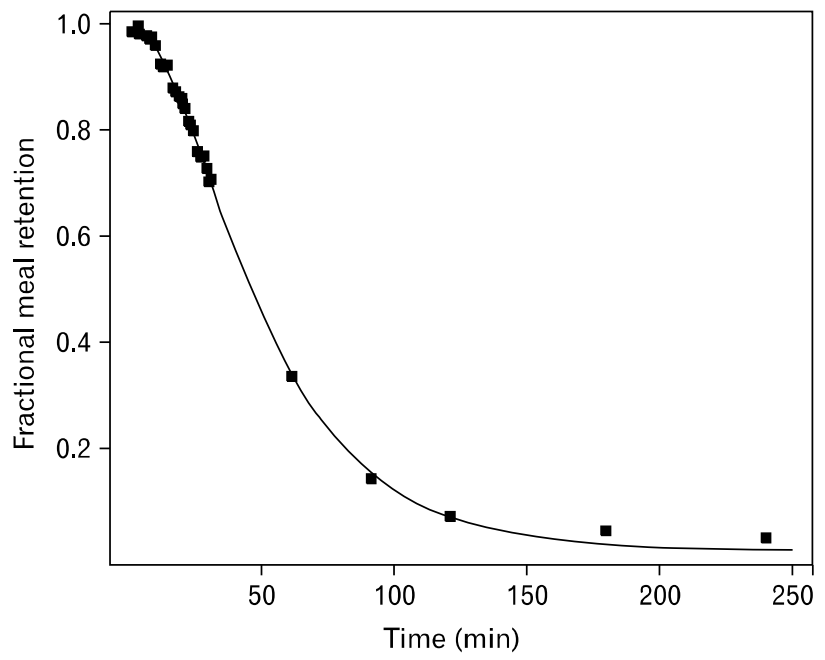

Figure 1. Examples of gastric images and regions of interest (A), gastric emptying data and fitted curve (B) using modified power exponential function in one healthy volunteer. 
0.9 , lag time and gastric emptying half time $\left(\mathrm{GE} \mathrm{T}_{1 / 2}\right)$ were additionally calculated using all acquired data by mathematical method using Couturier's formula ${ }^{14}$ and equal to $\ln \beta / \mathrm{k}-(\beta-1) / \mathrm{k} \beta$ and $-\ln \left(1-0.5^{1 / \beta}\right) / \mathrm{k}$, respectively. For practical clinical application, recalculation of every lag time and gastric emptying half time was performed using only 7 data points at $0,0.5,1,1.5,2,3$ and 4 hours.

\section{Statistical Methods}

Data were expressed as median (5-95th percentiles) for skewed distributed values. For normal distributed value, data were expressed as means (standard deviation). Data were compared using the Mann-Whitney $U$ test, Kruskal-Wallis test, one-way ANOVA or repeated measures ANOVA when suitable. The differences were considered significant when $P$-value was less than 0.05. Ratio data were correlated using Pearson's correlation. Agreement of lag times, gastric emptying half times and recalculated values were assessed with intraclass correlation coefficient (ICC). All data were analyzed using the SPSS software (version 16.0, SPSS Inc, Chicago, USA).

\section{Results}

One hundred and eighty-nine of 192 volunteers (99 females, body mass index 23.8 [3.9] kg/m², aged 43.5 [13.9] years) completed the study. Three volunteers who had dizziness or fainted during the scan acquisition, possibly due to prior prolonged fasting, were excluded from the study.

An example of gastric emptying data and fitted curve using modified power exponential function is shown in (Fig. 1). From 189 volunteers' gastric emptying data, $183(96.8 \%)$ data could be fitted with modified power exponential function with goodness of fit of more than 0.9 .

The descriptive statistics of gastric emptying are shown in table. There were no significant differences between GE $T_{1 / 2}$, percent gastric retentions at 1, 1.5, 2, 3 and 4 hours from 7 centers participating the study. However, significant differences between lag times and percent gastric retentions at 0.5 hour among several centers were demonstrated.

\section{Gender, Menstrual and Pill Effects on Gastric Emptying}

Female volunteers had significantly prolonged GE $\mathrm{T}_{1 / 2}$ and significantly higher percent gastric retentions $(P<0.001)$ than male volunteers (Table).

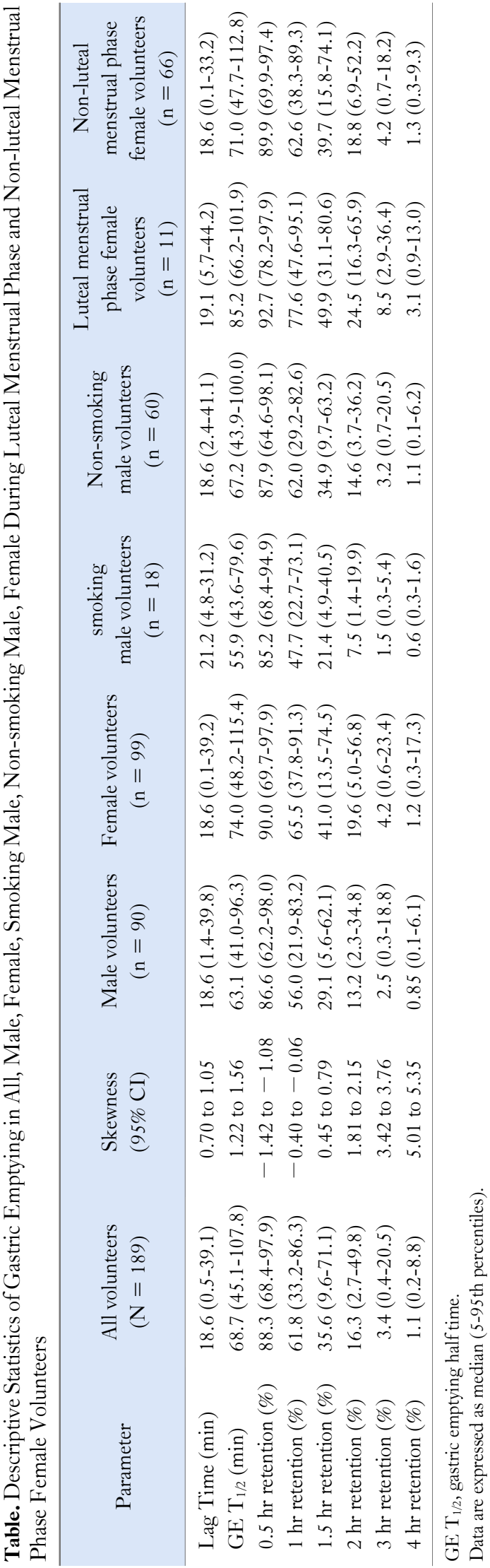


In female volunteers, those who were in luteal phase of menstrual cycle $(\mathrm{n}=11)$ had significantly prolonged $\mathrm{GE} \mathrm{T}_{1 / 2}(P<$ $0.05)$ and significantly higher percent gastric retentions $(P<$ $0.05)$ than those who were in follicular phase $(n=31)$. Those who were in menopause $(n=35)$ had no significant difference in $\mathrm{GE}_{1 / 2}$ or percent gastric retentions compared to those who were in follicular phase but had significantly shorter $G E \mathrm{~T}_{1 / 2}(P<$ $0.05)$ and significantly lower percent gastric retentions $(P<$ 0.05 ) than those who were in luteal phase (Fig. 2).

Female volunteers who were on contraceptive pills $(\mathrm{n}=6)$ had significantly prolonged GE $\mathrm{T}_{1 / 2}(P<0.05)$ than those who were in follicular phase or menopause but no significant differences in lag time, GE $\mathrm{T}_{1 / 2}$, or percent gastric retentions $(P>$ $0.05)$ as compared to those who were in luteal phase.

There was no significant difference between ages of male and female volunteers (43.7 [14.1] and 43.4 [13.7], respectively, $P$ $>0.05$ ). Compared to male volunteers, subgroups of female volunteers which were in menopausal status, follicular phase or luteal phase had significantly prolonged $\mathrm{GE} \mathrm{T}_{1 / 2}(P<0.05)$, and significantly higher percent gastric retentions $(P<0.05)$. Subgroup re-analysis of gastric emptying values of women in different menstrual status and non-smoking men were performed to exclude the confounding effect of smoking which was only found in male volunteers in our study. Only female volunteers who were in luteal phase had significantly prolonged $\mathrm{GE} \mathrm{T}_{1 / 2}(P<0.001)$

A

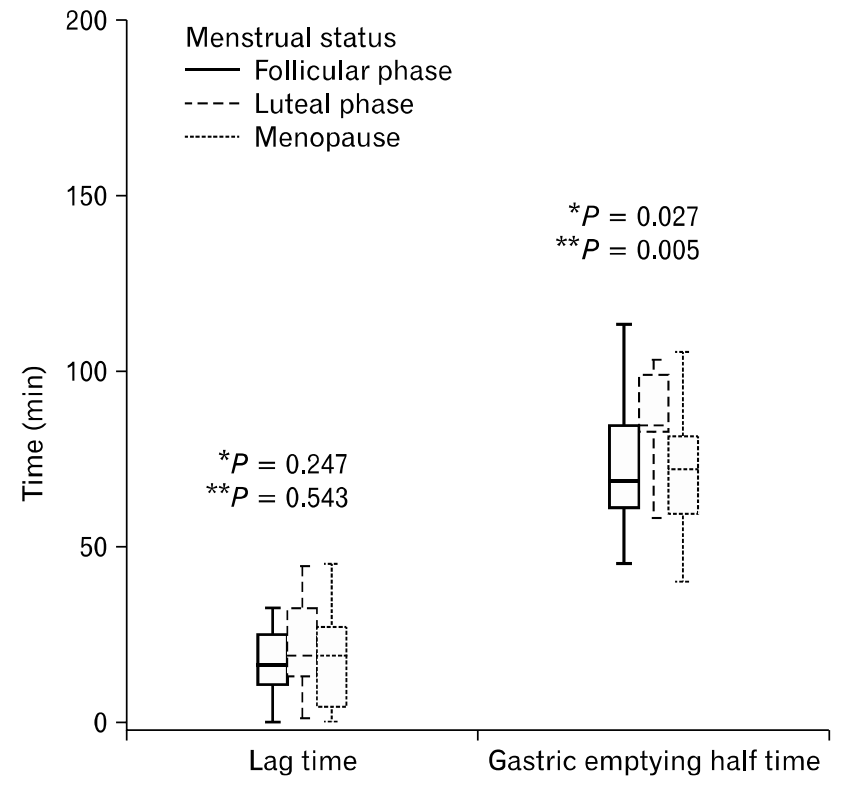

and significantly higher percent gastric retentions $(P<0.01)$ compared to non-smoker male volunteers.

\section{Smoking Effect on Gastric Emptying}

All of smoking and ex-smoking volunteers were male and had withheld from smoking for 2 to 72 hours before the study. Smoker male volunteer $(\mathrm{n}=18)$ had significantly shorter GE $\mathrm{T}_{1 / 2}(P<0.05)$ and significantly lower percent gastric retentions $(P<0.01)$ than non-smoker males $(\mathrm{n}=60)$. There was no significant difference between lag time, GE $\mathrm{T}_{1 / 2}$ and percent gastric retentions between ex-smoker $(\mathrm{n}=12)$ and non-smoker male volunteers (Fig. 3).

\section{Age and Body Mass Index Effects on Gastric Emptying}

There were no significant correlations between age and gastric emptying parameters including lag time, $\mathrm{GE}_{1 / 2}$ or percent gastric retentions at $0.5,1,1.5,2,3$ and 4 hours (correlation coefficients of $-0.006,-0.060,-0.015,-0.030,-0.045,-0.004$, -0.026 and 0.012 , respectively $(P>0.05)$.

There were also no significant correlations between body mass index and lag time, GE $T_{1 / 2}$ or percent gastric retentions at $0.5,1,1.5,2,3$ and 4 hours (correlation coefficients of -0.071 , $-0.093,-0.028,-0.034,-0.015,0.004,0.003$ and 0.003 , respectively $[P>0.05])$.

B

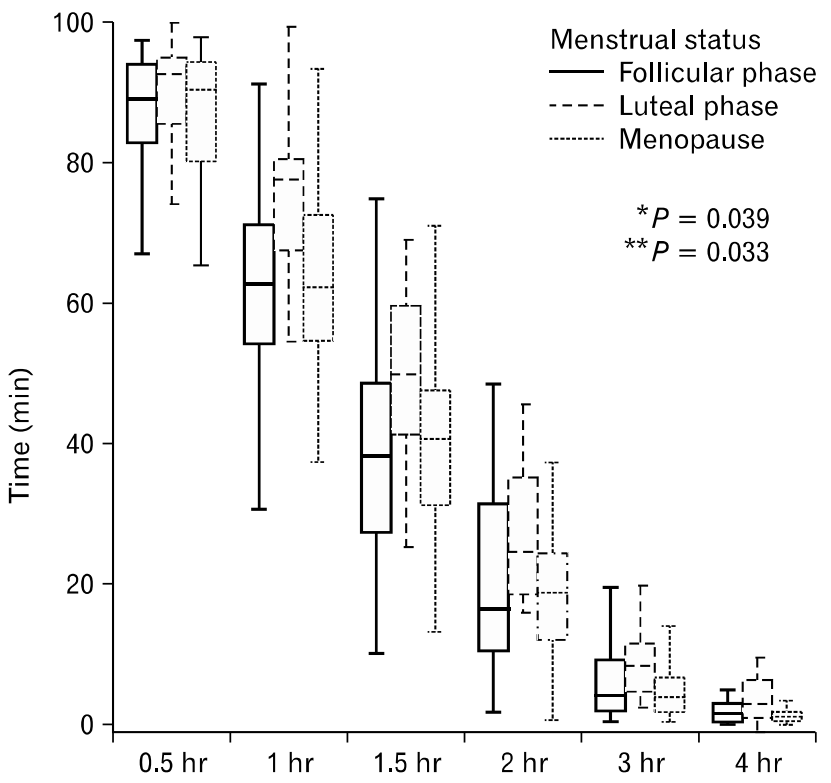

Figure 2. Box and whisker plots of female lag time, gastric emptying half time $\left(\mathrm{GE} \mathrm{T}_{1 / 2}\right)(\mathrm{A})$ and percent gastric retention (B) classified by menstrual status, ${ }^{*}$ follicular phase vs. luteal phase, ${ }^{* *}$ luteal phase vs. menopause. 
A

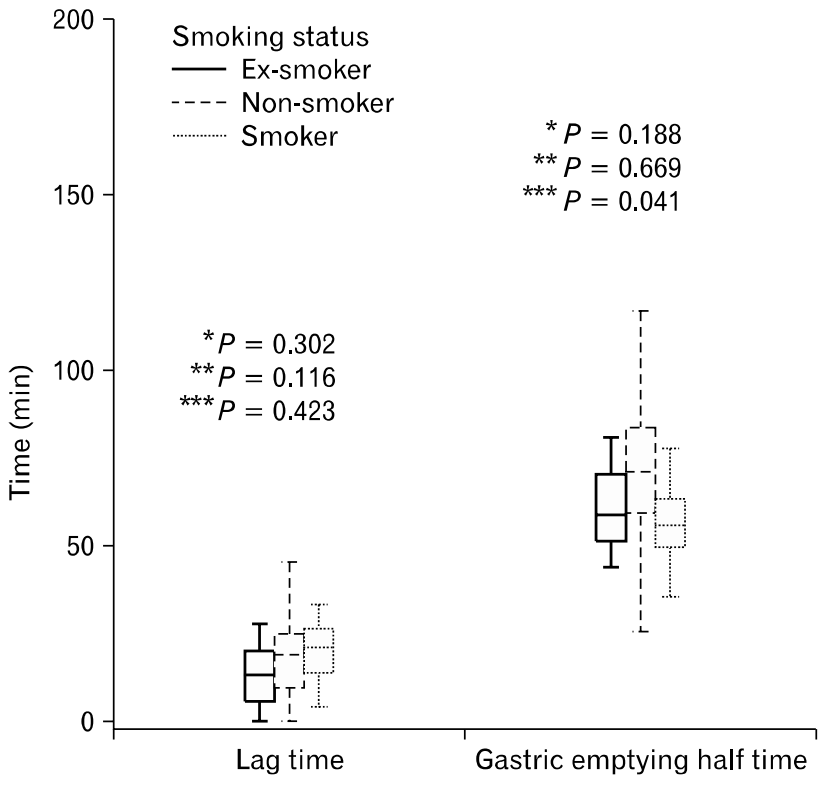

B

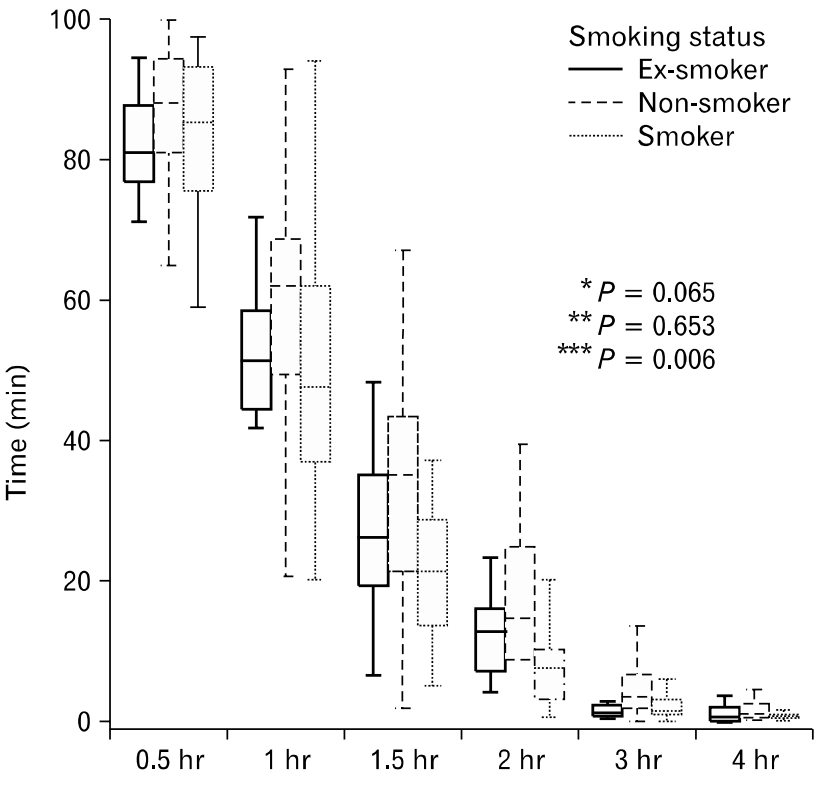

Figure 3. Box and whisker plots of male lag time, gastric emptying half time (GE $\left.\mathrm{T}_{1 / 2}, \mathrm{~A}\right)$ and percent gastric retention (B) classified by smoking status, *ex-smoker vs. non-smoker, ${ }^{* *}$ ex-smoker vs. smoker, ${ }^{* * *}$ non-smoker vs. smoker.

\section{Alcohol Consumption Effect on Gastric Emptying}

As most drinkers were male (73\%) and most non-drinkers were female (75\%), separate male and female subgroup analyses of alcohol consumption status and gastric emptying were made to exclude the confounding affect of gender on gastric emptying. In both male and female subgroups, there were no significant differences of lag time, $\mathrm{GE} \mathrm{T}_{1 / 2}$ and percent gastric retentions between drinkers, non-drinkers and ex-drinkers.

\section{Recalculation of Lag Time and Gastric Emptying Half Time Using Less Data Points}

Using only 7 data points at $0,0.5,1,1.5,2,3$ and 4 hours for lag time and $\mathrm{GE}_{1 / 2}$ calculation, the recalculated $\mathrm{GE} \mathrm{T}_{1 / 2} \mathrm{re}-$ vealed excellent agreement $(\mathrm{ICC}=0.98)$ with original $\mathrm{GE} \mathrm{T}_{1 / 2}$ calculated using every acquired data points. For lag time, the agreement between original and recalculated values also showed high agreement $(\mathrm{ICC}=0.85)$.

\section{Discussion}

Gastric emptying scintigraphy has been recognized as gold standard in gastric emptying measurement for establishing diagnosis of either gastroparesis or rapid gastric emptying. However, multiple factors including patient-related factors and technical factors have been shown to affect the gastric emptying values. ${ }^{15}$ Lack of gastric emptying scintigraphic protocol standardization in various nuclear medicine centers and valid normal gastric emptying values for such a protocol have resulted in interpretation difficulties. The currently available largest international gastric emptying normative database were acquired from 123 healthy volunteers from multi-institutional studies using a Western-style meal consisting of a scrambled egg substitute, 2 slices of bread, strawberry jam and water. ${ }^{9}$ Most of Thai and Asian people are not familiar with such a meal, therefore, adoption of that protocol and normative database may not be possible. In our study, we used Asian-style, rice based meals composed of steamed rice, a microwaved egg and water which were well acceptable and tolerable by Thai healthy volunteers. The scintigraphic acquisition technique used for attenuation correction in this study was left anterior oblique method. The left anterior oblique method has been proven that give no significant differences in $\mathrm{GE}_{1 / 2}{ }^{16}$ or rates of gastric emptying ${ }^{17}$ as compared with the geometric mean method.

Our study showed significant differences between lag time and percent gastric retention at 0.5 hour among several centers, therefore, those values may be neglected in gastric emptying interpretation.

There were no significant correlations between age and solid 
gastric emptying found in our study, similar to the studies of Madsen ${ }^{18}$ and Kao, ${ }^{11}$ but in contrast to the study of Tougas et al ${ }^{9}$ that demonstrated more rapid gastric emptying in elderly patients.

The association between gastric emptying and body mass index is still controversial. Our study demonstrates no influence of body mass index in gastric emptying like those findings from the studies of Tougas et al ${ }^{9}$ and Hermansson and Sivertsson, ${ }^{19}$ but in opposition to the study of Madsen which revealed inverse correlation between body mass index and mean gastric emptying time of radiolabeled cellulose fiber ${ }^{18}$ and the study of Grybäck et $\mathrm{al}^{20}$ that showed shorter $G E T_{1 / 2}$ in obese subjects.

In agreement with prior studies, ${ }^{5,919-24}$ prolonged GE $\mathrm{T}_{1 / 2}$ in female as compared to male volunteers are also observed in our study. This is not likely to be affected by lag phase as there is no significant difference in both genders but seem to be related to the increase in gastric retention beginning after 1 hour in female volunteers. These findings are in concordance with Knight et $\mathrm{al}^{24}$ which demonstrated no significant difference in lag phases between men and women but woman had higher gastric retention. However, Bennink et al ${ }^{5}$ and Grybäck et $\mathrm{al}^{20}$ found that women had significantly prolonged lag phase when compared to men.

In women, our study shows slower gastric emptying in luteal phase subgroup compared to follicular phase subgroup and menopausal subgroup. This is congruent with the finding from the study of Gill et $\mathrm{al}^{25}$ which revealed slower emptying of solid-phase marker during luteal phase as compared to the follicular phase and also demonstrated correlation between solid gastric emptying impairment and elevated serum progesterone levels. Our study shows no significant differences between lag time, GE $T_{1 / 2}$ and percent gastric retention of women in follicular phase subgroup or women in menopausal subgroup compared to non-smoking males. These imply that increased serum progesterone level during luteal phase of menstrual cycle may be attributable to gender-related differences in gastric emptying of solid meal. This is against findings in the study of Hutson et $\mathrm{al}^{23}$ and Knight et $\mathrm{al}^{24}$ which found that premenopausal women in follicular phase also had slower solid emptying than men. The incongruity may be explained by the fact that both Hudson et $\mathrm{al}^{23}$ and Knight et $\mathrm{al}^{24}$ studies did not include smoking status in their analyses.

There have been conflicting results regarding smoking effect on gastric emptying. Some scintigraphic studies demonstrated that smoking delayed gastric emptying of solid food ${ }^{4,26,27}$ but one showed more rapid emptying of solid meal in smokers than in non-smokers. ${ }^{12}$ The study of Sanaka et a ${ }^{28}$ using ${ }^{13} \mathrm{C}$-oc- tanoic breath test also found accelerated gastric emptying after actively smoking. In the present study, all smokers were male. We found that smoking male volunteers had more rapid solid gastric emptying than non-smoking male volunteers.

As there were high agreements between the original lag times and GE $T_{1 / 2}$ calculated by every acquired data points and recalculated values using only 7 data points as described in method part, the clinical gastric emptying scintigraphy can then be performed more conveniently with only 7 time points acquisition (at $0,30,60,90,120,180$ and 240 minutes after the standard meal ingestion).

There are some limitations of the study as western patients may not be familiar with rice-based meal. Also, quantitative analysis of alcohol effect on gastric emptying was not performed and their effect may not be reliable from our study.

In summary, this multicenter study provides normal solid gastric emptying values using Asian-style rice-based meal scintigraphy. We found that gender, menstrual status and smoking affected gastric emptying. For males, there should be separated database for normal values for smokers and non-smokers, whilst for females different normal values should be used for each phase of the menstrual cycle.

\section{References}

1. Lin HC, Prather C, Fisher RS, et al. Measurement of gastrointestinal transit. Dig Dis Sci 2005;50:989-1004.

2. Doran S, Jones KL, Andrews JM, Horowitz M. Effects of meal volume and posture on gastric emptying of solids and appetite. Am J Physiol 1998;275(5 Pt 2):R1712-R1718.

3. Moore JG, Datz FL, Christian PE, Greenberg E, Alazraki N. Effect of body posture on radionuclide measurements of gastric emptying. Dig Dis Sci 1988;33:1592-1595.

4. Scott AM, Kellow JE, Shuter B, Nolan JM, Hoschl R, Jones MP. Effects of cigarette smoking on solid and liquid intragastric distribution and gastric emptying. Gastroenterology 1993;104:410-416.

5. Bennink R, Peeters M, Van den Maegdenbergh V, et al. Comparison of total and compartmental gastric emptying and antral motility between healthy men and women. Eur J Nucl Med 1998;25:12931299.

6. Jonderko K. Effect of the menstrual cycle on gastric emptying. Acta Physiol Pol 1989;40:504-510.

7. Goo RH, Moore JG, Greenberg E, Alazraki NP. Circadian variation in gastric emptying of meals in humans. Gastroenterology 1987; 93:515-518.

8. Donohoe KJ, Maurer AH, Ziessman HA, Urbain JL, Royal HD. Procedure guideline for gastric emptying and motility. J Nucl Med 1999;40:1236-1239.

9. Tougas G, Eaker EY, Abell TL, et al. Assessment of gastric emptying using a low fat meal: establishment of international control values. 
Am J Gastroenterol 2000;95:1456-1462.

10. Chaiwatanarat T, Mahachai V, Kladchareon N, Kullavanijaya P, Sriratanaban A, Isarasena $\mathrm{S}$. Gastric emptying time: a comparison between geometric mean and left anterior oblique methods. Chula Med J 1996;40:979-987.

11. Kao CH, Lai TL, Wang SJ, Chen GH, Yeh SH. Influence of age on gastric emptying in healthy Chinese. Clin Nucl Med 1994;19:401404.

12. Hanson M, Lilja B. Gastric emptying in smokers. Scand J Gastroenterol 1987;22:1102-1104.

13. Siegel JA, Urbain JL, Adler LP, et al. Biphasic nature of gastric emptying. Gut 1988;29:85-89.

14. Couturier O, Le Rest C, Gournay J, et al. Gastric emptying of solids: estimates of lag phase and constant emptying times. Nucl Med Commun 2000;21:665-675.

15. Abell TL, Camilleri M, Donohoe K, et al. Consensus recommendations for gastric emptying scintigraphy: a joint report of the American Neurogastroenterology and Motility Society and the Society of Nuclear Medicine. Am J Gastroenterol 2008;103:753763.

16. Ford PV, Kennedy RL, Vogel JM. Comparison of left anterior oblique, anterior and geometric mean methods for determining gastric emptying times. J Nucl Med 1992;33:127-130.

17. Maurer AH, Knight LC, Charkes ND, et al. Comparison of left anterior oblique and geometric mean gastric emptying. J Nucl Med 1991;32:2176-2180.

18. Madsen JL. Effects of gender, age, and body mass index on gastrointestinal transit times. Dig Dis Sci 1992;37:1548-1553.
19. Hermansson G, Sivertsson R. Gender-related differences in gastric emptying rate of solid meals. Dig Dis Sci 1996;41:1994-1998.

20. Grybäck P, Näslund E, Hellström PM, Jacobsson H, Backman L. Gastric emptying of solids in humans: improved evaluation by Kaplan-Meier plots, with special reference to obesity and gender. Eur J Nucl Med 1996;23:1562-1567.

21. Datz FL, Christian PE, Moore J. Gender-related differences in gastric emptying. J Nucl Med 1987;28:1204-1207.

22. Degen LP, Phillips SF. Variability of gastrointestinal transit in healthy women and men. Gut 1996;39:299-305.

23. Hutson WR, Roehrkasse RL, Wald A. Influence of gender and menopause on gastric emptying and motility. Gastroenterology 1989; 96:11-17.

24. Knight LC, Parkman HP, Brown KL, et al. Delayed gastric emptying and decreased antral contractility in normal premenopausal women compared with men. Am J Gastroenterol 1997;92:968-975.

25. Gill RC, Murphy PD, Hooper HR, Bowes KL, Kingma YJ. Effect of the menstrual cycle on gastric emptying. Digestion 1987;36:168174 .

26. Miller G, Palmer KR, Smith B, Ferrington C, Merrick MV. Smoking delays gastric emptying of solids. Gut 1989;30:50-53.

27. Nowak A, Jonderko K, Kaczor R, Nowak S, Skrzypek D. Cigarette smoking delays gastric emptying of a radiolabelled solid food in healthy smokers. Scand J Gastroenterol 1987;22:54-58.

28. Sanaka M, Anjiki H, Tsutsumi H, et al. Effect of cigarette smoking on gastric emptying of solids in Japanese smokers: a crossover study using the ${ }^{13} \mathrm{C}$-octanoic acid breath test. J Gastroenterol 2005;40: 578-582. 